\title{
DE LO SUBJETIVO A LO OBJETIVO EN LA JURISPRUDENCIA CONVENCIONAL, EN DOS EJEMPLOS
}

\author{
ANTONIO LÓPEZ CASTILLO \\ Catedrático (A) de Derecho constitucional \\ Universidad Autónoma de Madrid
}

SUMARIO

I. Consideraciones introductorias. II. De la enfatización subjetivista a la objetivada contextualización de la tutela de la invocada libertad religiosa en el (inclusivo) sistema escolar... III. ...y a la acentuada salvaguarda de la convivencia en los espacios públicos, a la luz de la doctrina S.A.S. c. Francia. IV. Una consideración final, a modo de conclusión.

\section{CONSIDERACIONES INTRODUCTORIAS}

El espacio ius fundamental europeo se gesta, en el tracto de la evolutiva integración del CEDH, en una densa tarea de interpretación de sus cláusulas sustantivas, al efecto de comprender novedosos desafíos y realidades cambiantes, mediante una paulatina ampliación de sus márgenes conceptuales y mediante la inferencia de una ínsita faceta procedimental, en textos de inalterado tenor que, de no integrarse evolutivamente, habrían decaído en su aplicación al interno de unos sistemas constitucionales en los que el desarrollo y regulación de derechos y libertades cumple, en primer término, al legislador.

Y en ello estriba, y en eso se traduce, la caracterización ya recurrente de los estándares convencionales como derecho viviente, como referencia expresiva de su actualizada decantación jurisprudencial ${ }^{1}$.

1 En palabras (traducidas para la ocasión) de Zagrebelsky: «La Corte (europea de derechos humanos) practica una interpretación y una aplicación del Convenio (CEDH), que ella misma define como dinámica y evolutiva. Se está — prosigue diciendo - en presencia de un ejemplo claro de la función creativa de la interpretación judicial», La Corte europea dei diritti dell'uomo dopo sessant'anni. Pensieri di un giudice a fine mandato, en Il Foro italiano, 7-8, V, 2012.

A propósito de la categoría, en una comprensiva perspectiva de los ordenamientos constitucionales europeos e iberoamericanos de tradición jurídica continental, cf., por otros, Cavino (ed.), Esperienza di diritto vivente. La 
En la Europa de entre siglos, al reforzamiento de esta línea operativa de acompasada vivificación del CEDH se habría venido a sumar una adicional dimensión completiva de tutela. En tanto que, a la declaración de las medidas puntuales o singulares relativas a los diversos casos enjuiciados, se suma la adopción ocasional de medidas generales, de alcance reparador-preventivo, mediante la conocida técnica de los casos piloto (asuntos en los que, mediante el enjuiciamiento de una de muchas manifestaciones, se declara la salida a una falencia estructural o sistémica, de recurrente ineficacia o carencia de remedios de tutela; de modo que, sobre el reconocimiento de la vulneración de una determinada cláusula convencional, el TEDH se erige en garante de la convencionalidad de los poderes públicos estatales, incluido el legislador $)^{2}$.

La enfatización de las cláusulas del CEDH que resulta de esta extensiva praxis de la jurisdicción convencional cohabita con una praxis de contención que, mediante retorno al comodín de la cláusula de subsidiariedad refleja en el «margen de apreciación nacional», se mueve del énfasis subjetivista de la tutela convencional, particularmente evidente en casos de salvaguarda de la faceta negativa de la libertad de religión y de la cláusula de inmunidad de coacción, a la consideración objetivada de los marcos y espacios de confluencia (mediante una mirada novedosa, que no nueva, porque en esa línea, se había pronunciado reiteradamente la antigua Comisión, ComEDH, a lo largo de cuatro décadas de funcionamiento del sistema convencional de tutela, antes de dejar paso al nuevo sistema de TEDH permanente), al efecto de asegurar que los ámbitos nacionales de aplicación se mantienen como espacios comprensivos, aunque restrictos, no excluyentes, del sustrato comunitario/acervo constitucional que, desde su entrada en vigor, el CEDH contribuye a sustentar.

Pues bien, en lo que sigue, se va a tratar de esto último, poniendo el foco en dos casos; relativo, el uno, a la controvertida exigencia de inclusión educativa en el reglamentado espacio de la enseñanza escolar (II), y a propósito, el otro caso, de la tajante salvaguarda de la neutralidad de espacios públicos en los que se desenvuelve la convivencia social, mediante una previsión legislativa excluyente, de prohibición general (excepción hecha del entorno de los templos religiosos, según se ha de ver), de la presencia de personas portando vestimenta que tenga el efecto de simular y ocultar el rostro a los demás (III). Tras la consideración de esos dos referentes del apuntado tránsito, desde un enfatizado subjetivismo hacia la contextualizada objetivación de la prestación de tutela convencional, sería ya momento de formular alguna consideración final, a modo de conclusión (IV).

giurisprudenza negli ordenamenti di diritto legislativo, vol. I, Giuffre, 2009 y Bruno/Cavino (eds.), Esperienze di diritto vivente. La giurisprudenza negli ordinamenti di diritto legislativo, vol. II, Giuffre, 2011.

2 Y, no sin matices, aun el propio procedimiento de reforma (simplificada) de la Constitución; cf., a propósito de la pretendida contravención de convencionalidad de una reforma constitucional suiza que se consideraba lesiva de garantías convencionales, la elusiva remisión ad casum de la controvertida sentencia del TEDH, de 29 de noviembre de 2009, que, a propósito del encaje convencional de la previsión, previo referéndum ad hoc, de una regla constitucional del siguiente tenor: «La construcción de minaretes está prohibida» (artículo $72.3 \mathrm{CH}$ ), elude la cuestión en virtud de una restricta interpretación de la noción de «víctima» como requisito de legitimación, apuntando a la potencial interpretación constitucional de conformidad con el CEDH, por parte de la jurisdicción del Tribunal Supremo suizo (cf., a propósito, las dudas expuestas, en la doble perspectiva constitucional e ius internacional, por PETERs, El referéndum suizo sobre la probibición de minaretes (trad. F. Reviriego), en TRC 25, 2010, pp. 429-438). 


\section{DE LA ENFATIZACIÓN SUBJETIVISTA A LA OBJETIVADA CONTEXTUALIZACIÓN DE TUTELA DE LA INVOCADA LIBERTAD RELIGIOSA EN EL (INCLUYENTE) SISTEMA ESCOLAR...}

\section{Consideraciones preliminares}

Al hablar de enseñanza y de educación en relación con el Estado constitucional y la tutela de los derechos fundamentales, se impone recordar que se habla de la transmisión de conocimientos y de valores comunes y relativos a la convivencia democrática. Y que, en ese marco de aprendizaje, se contribuye a la gestación de autonomía personal sin perjuicio de una faceta cívica sin la que resultaría inviable la convivencia entre los diversos. Recuérdese, en este punto, la expresiva imagen de la oferta de una dieta moral en la escuela, de bajas calorías identitarias, como vía de gestación más segura de una moral, integrada de razón pública, modulando la concurrencia en el aula de morales privadas fuertes, al servicio del asentamiento de un espacio firme para la convivencia ${ }^{3}$.

La invocación a propósito de cláusulas convencionales, directamente o bien mediante su invocación conjunta con previsiones constitucionales (tales como la del artículo 27. 3 CE, aplicables a la luz de los estándares convencionales sentados al interpretar el contenido y alcance de la cláusula convencional del artículo 2, segunda frase, del Protocolo Adicional al CEDH), se habría de cohonestar, en todo caso, con el reconocimiento del derecho de todos, incluidas personas de origen extranjero (aun en situación irregular ${ }^{4}$ ), a una «educación integral», en el sentido que resulta del estándar convencional sentado al interpretar el sentido y alcance del artículo 2, primera frase, del referido Protocolo Adicional; en línea, por lo demás, de la consensuada expresión del común referente convencional ${ }^{5}$.

La «moral privada» que justifique una pretensión de objeción o excusa de seguimiento de unos determinados contenidos o materias curriculares en el sistema público de

3 A propósito de la jurisprudencia convencional, con referencias adicionales, López Castillo, Derecho a la educación en el artículo 2 del Protocolo núm. 1 al CEDH, en Monereo Atienza / Monereo Pérez (coords.), La garantía multinivel de los derechos fundamentales en el Consejo de Europa, Comares, Granada, 2017; y, respecto de la jurisprudencia constitucional española, cf. López Castillo, Artículo 27 (1-9) CE, en Rodríguez-Piñero / Casas (dirs.), Comentarios a la Constitución española, XL aniversario, Ed. Wolters Kluwer, Madrid, 2018.

4 Se ha de tener presente, si al ordenamiento constitucional español se mira, que la «educación en valores» bien puede contribuir a la configuración de una cierta «moral pública», en virtud del artículo 27.2 CE (interpretado a la luz, por ejemplo, del artículo 29.1 del Convenio internacional sobre los derechos del niño) que, sin adoctrinamientos, ni dogmatismos, sin verdades ni credos oficiales, asegura un suelo firme a la convivencia. Hablar de «moral pública» en oposición a pretensiones de tutela judicial efectiva sustentadas en la invocación de firmes y serios mandatos de conciencia, en el Estado constitucional de Derecho y de derechos, es hablar de un elemento integrante de la cláusula constitucional (y convencional) del orden público protegido por la ley, como expresamente dice el artículo 16.1, in fine, CE. Lo que no se ha de confundir necesariamente con un título de limitación de las diversas manifestaciones de la «moral privada».

5 Cf. Resolución 2163, de la Asamblea parlamentaria del Consejo de Europa, de 27 de abril de 2017, relativa a la protección de los derechos de los padres e hijos pertenecientes a minorías religiosas; y, asimismo, Recomendación 2101, 2017, al efecto de que el Comité de ministros la transmita a los gobiernos de los Estados miembros y desarrolle directrices sobre cómo proceder para una razonable acomodación entre la salvaguarda de profundas creencias morales o religiosas individuales y el aseguramiento del respeto de los derechos de otros (y, como presupuesto, doc. 14260 , de 31 de enero de 2017, ponente Valeriu Ghiletchi, del grupo del partido popular europeo). 
enseñanza podría modular la discrecionalidad política de las autoridades responsables de la elaboración del currículo y puede cuestionar, de modo casuístico, su modo de impartición. Pues, esa especie de «moral pública» que anida en el atributo «integral» del sustantivo educación (o enseñanza, instrucción), sin sustituir ni desplazar la «moral privada», podría contribuir a limitar su puesta en práctica mediante el pretendido ejercicio de una determinada conducta al amparo de un derecho fundamental (como el derecho a que los hijos no reciban educación en disconformidad con sus convicciones), a condición de asegurar una interpretación constitucionalmente conforme de la ley, lo que no sería practicable sin un preciso escrutinio de los posibles efectos derivados de la injerencia que se cuestione, mediante la estricta interpretación de los criterios integrantes del principio de proporcionalidad.

Todo ello, atendiendo a la incontestable reacción social que la creciente heterogeneidad de las sociedades contemporáneas genera, en espacios de confluencia marcados por la desconfianza alimentada por episodios expresivos de un terrorismo de matriz ideológico-religiosa, que encierra un cierto potencial de mediata descomposición, si no de inmediata fractura, de la convivencia.

Pues bien, a esa mutación ambiental no parece del todo ajena la evolutiva traslación del foco en la jurisprudencia (constitucional y) convencional, de lo individual a lo social, de la centralidad de la dimensión negativa del ejercicio del derecho de libertad (ideológica y religiosa, en particular, en su proyección al ámbito de la enseñanza), que caracteriza la aproximación jurisprudencial en los años ochenta y noventa del pasado siglo, al énfasis en la objetivación de sus posibles efectos dañinos sobre la convivencia, que pareciera marcar, ya netamente, algunos pronunciamientos más recientes.

Un cambio semejante de enfoque —y no solo a propósito de las cláusulas ideológico educativas - invita, al margen de su valoración crítica desde una estricta perspectiva ius fundamental, a la reflexión acerca de la reconsideración del sentido y alcance convencional (en tanto que elemento estructural a ese sistema de tutela de derechos y libertades en el marco de sociedades democráticas) del principio de subsidiariedad ${ }^{6}$ y de su instrumental directriz de reconocimiento del margen discrecional de actuación de los Estados parte del $\mathrm{CEDH}^{7}$.

La cuestión es que, en su evolutiva formulación, bien puede tomarse como punto de inflexión en la jurisprudencia del TEDH la reconsideración del estricto reconocimiento de la dimensión negativa de la libertad invocada frente a la presencia del crucifijo en la escuela italiana dando paso, en virtud de una comprensiva objetivación del supuesto en el marco de reconocimiento de un amplio margen de discrecionalidad en la materia. En

6 Subsidiariedad que deviene tanto más intensa, si del ya referido derecho educativo de los padres se trata, como bien ilustran los debates que están en el origen de su articulación convencional. Pues, a la presupuesta discrecionalidad estatal en la materia, ex artículo 2, primera frase, del Protocolo Adicional, se suma una remanente libertad de las familias, ex artículo 2, segunda frase, del Protocolo Adic, que bien pudo haberse subrayado si, contra lo que fuera finalmente el caso, ello se hubiese establecido mediante un inédito párrafo tercero del vigente artículo 12 CEDH; cf., a propósito, mi contribución («Derecho a la educación, en el artículo 2 del Protocolo núm. 1 al CEDH»), en Monereo Atienza / Monereo Pérez, 2017.

7 A propósito de esta auténtica directriz hermenéutica cf., por otros, García Roca, El margen de apreciación nacional en la interpretación del Convenio Europeo de Derechos Humanos: soberanía e integración, Ed. Civitas-Thomson Reuters, Madrid, 2010; BJorge, Domestic Application of the ECHR: The Courts as Faithful Trustees, OUP, Oxford, 2015. 
este sentido, salvado el límite del adoctrinamiento, nada en la Convención obstaría el hecho de que, como expresivo trasunto de la comunidad de tradición (cultural antes que cultual), un símbolo tal pudiera cohonestarse con las exigencias ius fundamentales y una exigencia de neutralidad, respecto de la que sigue abierto el debate en Italia y, por extensión, en el espacio europeo.

De este modo, en el contexto de un inusitado debate procesal, sin práctica solución de continuidad, de la lectura subjetivista de la sentencia Lautsi I, de 3 de noviembre de 2009, se pasaría ya a la objetivada contextualización de las pretensiones, mediante la sentencia de Gran Sala, Lautsi II, de 18 de marzo de 2011. Pues, como expresamente se afirma en su párrafo 73: «El Tribunal observa que en su sentencia de 3 de noviembre de 2009, la sala (...) sostuvo la tesis según la cual la exposición de crucifijos en las aulas, tuvo un impacto notable sobre el segundo y tercer demandante, de once y trece años en la época de los hechos. Según la sala, en el contexto de la educación pública, el crucifijo, que es imposible dejar de remarcar en las aulas, se percibe necesariamente como parte integrante del medio escolar y puede ser considerado por lo tanto como un «signo exterior fuerte » en el sentido de la mencionada decisión Dablab (ver los párrafos 54 y 55 de la sentencia). La Gran Sala no comparte esta postura. Estima que en este caso no puede basarse en dicha decisión al ser las circunstancias de ambos asuntos completamente diferentes. Recuerda que el asunto Dablab se refería a la prohibición realizada a una profesora de llevar el velo islámico en el marco de su actividad de enseñanza, prohibición motivada por la necesidad de preservar los sentimientos religiosos de los alumnos y sus padres y de aplicar el principio de neutralidad confesional de la escuela consagrado en derecho interno. Tras haber puesto de relieve que las autoridades habían sopesado debidamente los intereses en causa, el Tribunal decidió, en particular a la vista de la escasa edad de los niños a cargo de la demandante, que dichas autoridades no habían sobrepasado su margen de apreciación» ${ }^{8}$.

$8 \mathrm{Y}$, en lo siguiente, se añade: «Por otro lado, los efectos de la visibilidad creciente que la presencia de crucifijos otorga al cristianismo en el espacio escolar merecen ser incluso más relativizados en vista de los siguientes elementos. Por una parte, esta presencia no se asocia a la enseñanza obligatoria del cristianismo (ver los elementos de derecho comparado expuestos en la sentencia Zengin, § 33). Por otra parte, según las indicaciones del Gobierno, Italia abre paralelamente el espacio escolar a otras religiones. El Gobierno indica especialmente que no está prohibido que los alumnos lleven el velo islámico y otros símbolos y vestimentas con connotación religiosa y que se prevén arreglos para facilitar la conciliación de la escolarización y de prácticas religiosas no mayoritarias, el comienzo y el fin del Ramadán «se festejan a menudo» en las escuelas y en los establecimientos se puede adoptar una enseñanza religiosa facultativa para «todas las confesiones religiosas reconocidas» (párrafo 39). Además, nada indica que las autoridades se muestren intolerantes respecto a los alumnos adeptos a otras religiones, no creyentes o poseedores de convicciones filosóficas no relacionadas con religión alguna. Además, los demandantes no pretenden que la presencia del crucifijo en las aulas les incitara al desarrollo de prácticas de enseñanza que presentaran una connotación proselitista, ni sostienen que el segundo y tercero de los mismos se encontraran confrontados a un profesor que, en el ejercicio de sus funciones, se hubiera apoyado tendenciosamente en esta presencia» (párrafo 74). «Finalmente, el Tribunal observa que la demandante conservó enteramente su derecho, en su cualidad de progenitora, de esclarecer y aconsejar a sus hijos, de ejercer con ellos sus funciones naturales de educadora y de orientarlos en una dirección, conforme a sus propias convicciones filosóficas (ver, especialmente, las sentencias Kjeldsen, Busk Madsen y Pedersen y Valsamis, $\$ \$ 54$ y 31, respectivamente)» (párrafo 75). «De lo anterior se deduce que al decidir mantener el crucifijo en las aulas de la escuela pública frecuentada por los hijos de la demandante, las autoridades actuaron en los límites del margen de apreciación del que dispone el Estado demandado en el marco de su obligación de respetar, en el ejercicio de las funciones que asume en el terreno de la educación y la enseñanza, el derecho de los padres de garantizar esta educación y esta enseñanza conforme a sus convicciones religiosas y filosóficas» (párrafo 76). «El Tribunal deduce que no ha habido violación del artículo 2 del Protocolo n. ${ }^{\circ}$ 
En consecuencia con esa especie de ajuste consecuencialista, bien puede decirse que «en la jurisprudencia más reciente del TEDH no faltan los casos en los que, no sin controversia, se aprecia la postergación del subjetivismo anterior, mediante una especie de objetivación de las expectativas de tutela convencional, que, de no acreditarse su compatibilidad con el principio democrático... no se considerarían ya suficientes al efecto de declarar un incumplimiento de la correspondiente garantía del CEDH», de modo que «sobre la posible invocación de la cláusula de abuso de derecho, ocasionalmente aplicada, en relación con supuestos de pretendida subversión de los sistemas constitucionales de los Estados parte del $\mathrm{CEDH}^{9}$ ), en la jurisprudencia constitucional se avanza en la sistemática y extensiva interpretación de las cláusulas de limitación de las garantías y derechos convencionales, mediante una casuística integración, comprensiva de elementos subjetivos y objetivos, en concurso, de la cláusula convencional de orden público» ${ }^{10}$.

\section{Un repaso contextualizado de Osmanoglou y Kocabas c. Suiza: ¿un asunto como otro cualquiera?}

Sabido es que, mediante sentencia de 10 de enero de 2017, la tercera sección del TEDH, presidida por Luis López Guerra, con base en su tradicional interpretación integrada de la comprensiva cláusula ius educativa del artículo 2 del Protocolo Adicional (PrAdic), ha dictado sentencia, en resolución de la demanda n. ${ }^{\circ}$ 29086/12, as. Osmanoglu y Kocabas/Suiza, declarando conforme al CEDH la cuestionada negativa de las autoridades escolares del Cantón de Basilea-Ciudad a eximir de la obligatoriedad de asistencia a clases de natación de dos hijas de ciudadanos suizos en posesión, asimismo, de su nacionalidad turca de origen.

Lo relevante del caso no está tanto en el expreso reconocimiento de un amplio margen de apreciación nacional, al pronunciarse acerca de la queja relativa a la imposición de cursos mixtos de natación a las dos hijas mayores de los recurrentes, como en la extensiva interpretación de la exigencia, cuya desatención sería objeto de sanción, por un total de 1400 francos suizos (algo menos, entonces, de 1300 euros); por lo demás, no obstante la falta de un compromiso convencional específico, puesto que Suiza no se había obligado expresamente con respecto al derecho reconocido en el ya referido artículo 2 PrAdic, los recurrentes pudieron plantear sus quejas, en vía interna y ante el TEDH, al amparo de la

1 respecto a la demandante. Considera además que no se plantea ninguna cuestión distinta en el terreno del artículo 9 del Convenio» (párrafo 77). «El Tribunal considera que, leída como debe ser a la luz del artículo 9 del Convenio y de la segunda frase del artículo 2 del protocolo $n .{ }^{\circ} 1$, la primera frase de esta disposición, garantiza a los alumnos un derecho a la instrucción en el respeto de su derecho a creer o no creer. Concibe en consecuencia que los alumnos partidarios de la laicidad vean en la presencia de crucifijos en las aulas de la escuela pública en la que están escolarizados un incumplimiento a los derechos que les confieren estas disposiciones. Sin embargo, estima que, por las razones indicadas en el marco del examen del caso de la demandante, no ha habido violación del artículo 2 del protocolo n..$^{\circ} 1$ respecto al segundo y tercer demandante. Considera además que no se plantea ninguna cuestión distinta en el terreno del artículo 9 del Convenio» (párrafo 78).

9 A propósito de esto, se remite aquí a mi contribución (España siglo xxi: ¿Desunión y/o Unión Europea? Trazas y manchado del boceto de un cuadro de situación), al libro homenaje al profesor J. J. Solozábal, CEPC/FGA, Madrid (en prensa).

10 Con esos entrecomillados términos se concluye mi contribución (La confluencia entre Tribunales Constitucionales, TEDH y TJUE), en AFDUAM 22, 2018, pp. 131-169 (166-7). 
genérica cláusula de libertad religiosa, ex artículo $9 \mathrm{CEDH}$, sin que el país denunciado adujese oposición procesal alguna.

En consecuencia, la falta de invocación de la lex specialis (artículo 2 PrAdic) no dificultó el enjuiciamiento convencional de una demanda en la que realmente se trataba de reafirmar el derecho de los padres (de origen turco) a objetar el seguimiento obligatorio de clases mixtas de natación por parte de dos de sus hijas (siendo que la normativa suiza de aplicación establecía la separación por sexos en esas clases, a partir de los doce años, y estando claro que en la invocada prescripción coránica ello no se ordenaba necesariamente antes de la pubertad).

La decisión recurrida ante el TEDH es una sentencia del TS de Suiza, de 7 de marzo de 2012, 2C_666/2011, que se inspiraría en una decisión de principio, de 24 de octubre de 2008, 135 I 79, mediante la cual se pasaba de poner el énfasis en la libertad individual a favorecer el interés público de promoción de la integración del extranjero ${ }^{11}$.

Recuérdese que, en su repaso al derecho comparado, la Sala del TEDH menciona resoluciones jurisdiccionales dictadas en otros dos Estados vecinos, Alemania y Liechtenstein. Pues bien, siendo de interés, esa complementaria referencia comparativa de la Sala produce cierta insatisfacción.

Pues, obviamente, no es lo mismo remitir a una decisión conciliadora de los intereses de la parte recurrente y del interés público, mediante equilibrada composición, en la que el elemento principal resulta ser la función integrativa de un sistema escolar que, en un espacio de neutralidad, pretende promover la confluencia y contraste de sendas ideas y creencias, culturas y costumbres, de los escolares (cf. sentencia del Tribunal federal de lo contencioso-administrativo), que invocar una sentencia, como la dictada por el Staatsgerichtshof de Liechtenstein, con fecha de 29 de octubre de 2012, a propósito de una semejante pretensión de excusar la asistencia a clases obligatorias de natación. Lo peculiar de ese fallo micro estatal no está tanto en la aceptación de la pretensión objetora de los padres de dos niñas y un niño (acordando admitir la excusa, sin perjuicio de la exigencia escolar a los padres de una acreditación de asistencia de los niños a clases externas de natación, y devolviendo los autos a la inferior instancia jurisdiccional), como en el razonamiento que la sostiene.

Y ese es —en síntesis — que, dado que no se trataba de musulmanes, el supremo interés público de integración de los extranjeros habría estado ausente en el caso. Un caso en el que — se enfatizaría - a diferencia de lo que, como doctrina general, se sentara en la sentencia del TS de Suiza, de 24 de octubre de 2008, que se toma como referente, se habría tratado de personas integradas, de esa sociedad (recuérdese, por lo demás, que los recurrentes del caso referido en el texto sumaban a la nacionalidad turca su condición de ciudadanos suizos) y que, en atención a su pertenencia a la llamada iglesia católica del Palmar, de no atenderse a su imperativo religioso, podrían resultar excomulgadas.

Pues bien, en la secuencia argumental de la Sala se advierte, en lo sustancial, un doble modo de razonar.

11 Cf., en esa misma línea, a propósito de alumna de credo chiita, de 14 años, enfatizando los elementos de acomodo a la pretensión que supondrían el hecho de poder vestirse con traje de baño conforme a sus creencias, de poder ducharse de modo independiente y de no tratarse de clases mixtas, restando importancia al hecho de que el enseñante no fuese mujer (sentencia TS de Suiza, de 11 de abril de 2013, 2C_ 1079/2012). 
De un lado, se cuentan las consideraciones del TEDH, en el marco del presupuesto margen de apreciación nacional, a propósito de la específica función de integración social que compete a la escuela, en donde a la transmisión de contenidos se sumaría un entorno de confluencia (eso que se viene a denominar «condiciones externas» de la enseñanza), y acerca de una línea de acomodo, que se opone al rechazo del compromiso paterno de que las hijas aprendieran a nadar siguiendo cursos privados, que se traduce en la oferta de acceso a duchas y vestuarios separados y al posible porte de un traje de baño homologado al efecto de observar sus creencias religiosas, el denominado «burkini»).

De otro lado, el TEDH se adentra en consideraciones relativas a datos numéricos y apreciaciones de corte sociológico, traídas al debate procesal por el Gobierno suizo; así, en particular, una alusión al aumento del número de extranjeros y al potencial incremento de pretensiones de objeción que ello podría traer consigo y, a mayor abundamiento, una ponderación del sesgo cambiante de la opinión pública ante esta deriva, como en una especie de registro de lectura de la temperatura de un termómetro ambiental.

$\mathrm{Ni}$ que decir tiene, la dificultad que resulta de asumir semejante sociologismo, al efecto de justificar una injerencia estatal en un espacio ius fundamental de autodeterminación, personal o, por extensión, familiar, en atención a la posición prevalente del objetivo de exitosa integración social. Si esa focalización de la cuestión de la objeción a las clases de natación, a la luz del dato sociológico y de la atmósfera ambiental, deja entrever una posible deriva en la consideración de unos u otros supuestos, según que el elemento de extranjería se halle más o menos presente, es cuestión sobre la que reflexionar. Pues, en buena técnica de interpretación ius fundamental, ese tipo de consideraciones acaso pudiera tacharse de técnica o criterio desalentador. Y, como es notorio, el efecto de desaliento en el ejercicio de los derechos fundamentales, ha sido otras veces determinante al efecto de declarar un incumplimiento estatal de las obligaciones convencionales (así, por ejemplo, como en otras resoluciones, en Folgero).

Que el legislador encuentre unos u otros compromisos, en atención a las mayorías sociales, es una cosa, y la invocación del estado de una determinada cuestión en la sociedad, por aproximación discursiva, es otra cosa, ya distinta; por más que la jurisprudencia de entre siglos se mueva en un sentido unidireccional, poniendo los énfasis ya no tanto en el reconocimiento de las libertades y derechos constitucionales y convencionales frente a cualesquiera afectaciones posibles de su dimensión negativa, como en la deferente tolerancia de lo diferente por las mayorías culturales y cultuales.

Se advierte, en efecto, una tendencia jurisprudencial a la deferencia convencional con la discrecionalidad del legislador estatal, y su consecuente aplicación por parte de las autoridades nacionales, en detrimento de aquella otra línea de jurisprudencia, de marcado acento subjetivista, en la que esa dimensión negativa o espacio de inmunidad de coacción de la libertad o derecho convencional parecía primar.

En lo sucesivo, una deriva semejante podría llevar a velar, de enfatizarse la insistencia en la perspectiva objetivada de la realización de los derechos en consonancia con las exigencias mayoritarias de articulación de la convivencia e insistiendo en la aplicación de las cláusulas limitativas - no tanto en relación con los propios derechos invocados, como a la luz de una cláusula de abuso de derecho-, una constitutiva dimensión subjetiva sin la que el sistema convencional de garantías no se podría entender. 


\section{III. ...Y A LA ACENTUADA SALVAGUARDA DE LA CONVIVENCIA EN LOS ESPACIOS PÚBLICOS, A LA LUZ DE LA DOCTRINA S.A.S. C. FRANCIA}

\section{Consideraciones generales, a propósito de la prevención normativa ante manifestaciones de «trasplante» cultural/cultual}

Mediante sentencia de 1 de julio de $2014^{12}$, el TEDH (salvada la discrepancia de dos de las integrantes de la Gran Sala, mediante voto particular ${ }^{13}$ ) ha declarado la no incompatibilidad con los artículos 8, 9, 10 y 14 del CEDH de la genérica prohibición, mediante ley (n. ${ }^{\circ}$ 2010-1192, de 11 de octubre), de simulación del rostro en lugares públicos (artículo 1: «Nadie puede portar, en el espacio público, una vestimenta destinada a disimular su rostro» $)^{14}$.

La norma (que parecía responder a la inquietud por la reciente aparición del llamado velo integral en el territorio nacional, inicialmente plasmada en un informe, con recomendaciones - la primera de las cuales era someter a votación una resolución reafirmando los valores republicanos y condenando como contraria a esos valores la práctica de porte del velo integral-, elaborado a instancia de la conferencia de presidentes de la Asamblea Nacional por representantes de los diversos partidos), entraría en vigor a partir del día once de abril de $2011^{15}$, abriendo una senda, de inmediato transitada por la ley belga de 1 de junio siguiente, cuya interdicción de portar vestimenta que disimulase el rostro en el espacio público, atendidos los objetivos que decía perseguir el legislador (la seguridad pública, la igualdad entre hombre y mujer y una cierta concepción de la «convivencia» en la sociedad), se tendría por expresión de una necesidad social imperiosa en una sociedad democrática, mediante sentencia del TC de Bélgica, de 6 de diciembre de $2012^{16}$; y, en lo sucesivo, no sin modulaciones de fondo y forma, ha podido tener un

12 Que resuelve el asunto S.A.S. c. France, demanda n. ${ }^{\circ} 43835 / 11$.

13 Las discrepantes, Nussberger y Jäderblom, habrían estimado desproporcionada una previsión normativa que, en su opinión, se habría debido considerar vulneradora de los artículos 8 y 9 CEDH.

14 Respecto de la interdicción, cuyo desconocimiento queda sujeto a sanción (multas o/y seguimiento de cursos de ciudadanía y, en caso de haber sido ello consecuencia de actos de imposición, prisión de uno o dos años y multa de treinta o sesenta mil euros para los responsables, según que se proyecte ello a personas mayores de edad o a menores, ex artículos 3 y 4, que modificara el Código penal, respectivamente), ex artículo 2, se precisa el ámbito de aplicación espacial (vías públicas y lugares abiertos al público afectados a un servicio público) y se delimita su alcance materia mediante una pormenorizada referencia de los supuestos excluidos (si se tratase de vestimenta prescrita o autorizada por disposiciones legislativas o reglamentarias, si estuviera justificada por razones de salud, o motivos profesionales, o se inscribiese en el marco de prácticas deportivas, festivas o de manifestaciones artísticas o tradicionales).

A propósito del detalle, cf. Circular del primer ministro, de 2 de marzo de 2011, reproducida en su literalidad, en el apartado C. de los antecedentes, y circulares de 11 y 31 de marzo de ese mismo año, de los ministerios de justicia e interior (ivi, apartado D, párrafos 32 y 33 , respectivamente).

15 Mediante Décision n. ${ }^{\circ}$ 2010-613, de 7 de octubre, el Consejo Constitucional francés, partiendo, así como de la tercera entrada del Preámbulo de la Constitución de 1946, de los artículos 4, 5 y 10 de la Declaración de derechos del hombre y del ciudadano, considera que el legislador habría alcanzado a conciliar la salvaguarda del orden público y la garantía de los derechos fundamentales objeto de protección constitucional, mediante una tarea de compleción y generalización de las reglas que hasta entonces se habían reservado a situaciones puntuales al efecto de salvaguarda del orden público, que (hecha la salvedad de una restricción de acceso y salida de los lugares de culto que, de mantenerse, resultaría lesiva del artículo 10 de la Declaración de 1789) se considera que no contrarían la Constitución.

16 Cf. la referencia a propósito en los antecedentes (En Fait, IV. A. párrafos 41 y 42) de la sentencia S.A.S. c. Francia cit. (cf., a. e., Ruet, 2014; y, en la doctrina española, entre otros, Olmedo, 2014, Gajardo, 2015, Camarero/ Zamora, 2015). 
relativo influjo, como elemento referente de contraste, en el desenvolvimiento de los debates públicos, a propósito, abiertos en otros Estados europeos, desde los Países Bajos ${ }^{17}$, a los casos de Austria o Alemania, o Dinamarca, entre otros ${ }^{18}$.

En los Países Bajos, de inicio a fin se ha transitado — dicho sea, a título jocoso- a caballo del (imprevisto) camino español ${ }^{19}$ y de la senda marcada por el republicanismo francés. En realidad, la iniciativa neerlandesa de negar el acceso público a personas que portasen velo integral viene de 2007. Y, al modo de ensayo y error, con variantes de flexibilización, desde la sola referencia inicial al burka, a la propuesta de restricta prohibición en los espacios escolares, volviendo luego al punto de partida, diríase a la francesa. Pero lo cierto es que a la previsión de sanciones penales a quienes pretendiesen portar en lugares públicos, fuera de los templos, vestidos que ocultasen el rostro por completo o dejando a la vista solo los ojos, se vino a oponer, mediante dictamen de 28 de noviembre de 2011, publicado el seis de febrero de 2012, el Consejo de Estado. El rechazo de aquella pretendida regulación general, por entender que ni respondía a necesidad social imperiosa alguna, ni era necesaria en una sociedad democrática.

Pese a todo, y no sin una relativa división en la sociedad, el resultado de todos esos debates ha sido la previsión, ya al inicio del verano de 2018, de una regulación de parcial prohibición, por la que se niega el acceso con el rostro cubierto a los transportes públicos, y hospitales, escuelas o edificios gubernamentales; lo que, dicho de otro modo, puede

Posteriormente, mediante sentencias del TEDH, de 11 de julio de 2017, dictadas en sendos asuntos Belcacemi y Oussar c. Bélgica y Dakir c. Bélgica, con base en la doctrina sentada en el asunto S.A.S. c. Francia, se reitera que una regulación como la establecida mediante ley de 1 de junio de 2011 (y otras disposiciones adoptadas por algunos municipios) pueden tenerse por proporcionadas a los efectos de salvaguarda de la convivencia y pueden pasar por necesarias en una sociedad democrática

17 Cfr. Ley de parcial prohibición de la ropa que cubre el rostro (Wet gedeeltelijk Verbod gezichts gezichtsbedekkende Kleding.

18 En Dinamarca, mediante ley, de 31 de mayo (en vigor desde el día uno de agosto) de 2018, en línea con el antecedente galo, se articula un régimen general de prohibición de presencia de trajes que oculten el rostro en los espacios públicos. Por lo demás, en esa línea, se ha movido también el ordenamiento constitucional de Bulgaria. En el caso de Alemania, mediante ley se ha establecido una regulación condicionada y restricta, de modo que se excluye esa opción personal en la policía, al tiempo que se establece la obligación de identificación en lugares y espacios públicos, incluida la deambulación por las calles, a requerimiento de la policía (de modo restricto al ámbito la función pública, se pretende reafirmar así, en Alemania, la neutralidad del Estado y de sus servidores públicos, salvaguardando la exigencia constitucional de prestación de lealtad al Estado por parte de sus funcionarios, ex artículo 33 LFB; de otra parte, aunque ya en un plano federado, se ha de mencionar, en este punto, la alternativa previsión de un específico régimen de total prohibición (a la francesa), en Baviera. Por lo demás, como tradicional espacio de debate a escala y en escalón, en un doble plano federado y federal, bien puede resultar de interés el estado de la cuestión en Suiza (desde las regulaciones previas en algunos cantones al debate federal pendiente de consulta referendaria, una vez alcanzado el límite de las cien mil firmas, en el año en curso).

19 Si bien en España no se ha regulado mediante la ley esta cuestión (dada la práctica cesura en Senado y Congreso de los Diputados), se recordará que mediante sentencia del Tribunal Supremo, de 6 de febrero de 2013 (dictada en casación de una previa sentencia del TSJ de Cataluña en la que la controvertida regulación municipal se había considerado compatible con las exigencias necesarias en una sociedad democrática) se acordaría la anulación de algunas previsiones de la ordenanza municipal de civismo y convivencia del Ayuntamiento de Lleida y otras previsiones reglamentarias relativas al acceso a archivos y locales municipales, en la medida en que, tratándose de injerencias sobre una conducta (la de portar el llamado velo integral) expresiva de libertad religiosa (preciso es retener, en este punto, que la restricción se hacía extensiva a otras prendas no connotadas religiosamente, como los pasa montañas, los cascos integrales o cualesquiera otros vestidos y accesorios que impidiesen o restringiesen la identificación y una comunicación visual), por su rango infra legal, esas regulaciones municipales tendrían vedada una regulación restrictiva semejante (otro juicio le merece, en cambio, esa restrictiva previsión reglamentaria en lo que se aplica al acceso al transporte público); a propósito de la cuestión, en perspectiva comparatista, cf. Alaez, 2011; Roca, 2017. 
decirse afirmando que, a diferencia del referente galo, mediante el compromiso holandés no se excluye la libertad de deambular por las calles con trajes que oculten o dificulten la visión del rostro.

\section{De la restricta modalización a una genérica regla general de prohibición}

A la altura de 2018, es bien notorio que la sentencia S.A.S. c. Francia ha supuesto un punto de inflexión, por lo que al debate europeo acerca de la regulación de prohibiciones de acceso a lugares públicos se refiere.

En un doble sentido, político y jurídico, y tanto en el plano regional europeo, como en el de los diversos ordenamientos nacionales, dicho sea esto, aquí, al margen de su respectivo estado de la cuestión.

Sobre el detalle de unas y otras previsiones, y sin perjuicio de la diversa respuesta ante ese (relativamente modesto) fenómeno ideológico-religioso, en el tracto que va de la primera a la segunda sentencia del TEDH dictada a propósito de recursos interpuestos contra una genérica prohibición (legislativa) de acceso a lugares públicos de personas con vestimenta de carácter (no solo) religioso que dificulte u obste por completo la visión del rostro de su portador/a, acaso pueda seguir considerándose como un ámbito falto de consenso, pero de otro modo.

Pues, sobre la consecuente invocación de la subsidiariedad de su jurisdicción a propósito del encaje convencional de regulaciones relativas a cuestiones atinentes al sustrato cultural y cultual de las comunidades nacionales de los Estados parte del CEDH, y la refleja apreciación de la concurrencia de un margen de apreciación nacional, de anchura y extensión inversamente proporcional al grado de precisión de los estándares convencionales sentados por el TEDH, en su sentencia S.A.S. c. Francia habría considerado el TEDH como algo legítimo, y acaso necesario, en una sociedad democrática, que el legislador nacional articulase su voluntad política (no ya de modo mayoritario, sino mediante la práctica unanimidad de los representantes en ambas Cámaras). Tomando, así, la decisión de avanzar, desde el tratamiento de la cuestión en la típica perspectiva de aplicación, más o menos rigurosa, de exigencia ex post de unas puntuales exigencias de orden público, hacia una regulación legislativa de genérica pretensión preventiva que, en su sintética simplicidad, contiene una reafirmación cultural y cultual de la nación francesa, al efecto de cuya salvaguarda se establece un régimen (penal) de sanciones y se prescribe el seguimiento obligado de un programa de formación cívica al efecto de promover los valores republicanos.

Y ello mediante la novedosa consideración del presupuesto inexcusable de la convivencia que supone, tanto más entre los distintos, que, con ocasión del ejercicio de las propias libertades y derechos (fundamentales), no se obstaculice ni desaliente a los demás en el ejercicio de sus respectivas libertades y derechos (fundamentales).

De ese modo, asumiendo en lo sustancial la justificación aducida por el legislador, legitimada al interno, mediante declaración de su conformidad constitucional, por parte del Consejo constitucional, y sostenida ante el TEDH por el Gobierno, la Gran Sala contribuiría, a su modo, al establecimiento de la aducida conexidad entre esa enfática llamada a la convivencia y una extensiva comprensión de la cláusula de orden público convencional, integrada a partir de una matizada consideración de sus respectivos 
términos en los artículos 8 y $9 \mathrm{CEDH}$, relativos a la intimidad y a la libertad de creencias, que estarían en la base de su decisión mayoritaria.

Pues bien, sobre la inmediata crítica doctrinal opuesta a la interpretación del TEDH, a propósito del reconocimiento de un amplio margen de apreciación nacional - y, en consecuencia, implícita retracción de su jurisdicción de control—, como presupuesto de su comprensiva aceptación del salto cualitativo que va de la regulación, más o menos intensa, de la aplicación casuística de los elementos integrantes de la cláusula de orden público, a la sustentación preventiva en esa misma cláusula de una regulación de alcance excluyente (en la medida en que se veda el acceso a la plaza pública — vale decir- a quienes oculten su rostro, pero no mediante cualesquiera prendas y en cualesquiera situaciones, como bien se colige del objetivo principal del informe que está en el origen de esa genérica prohibición ex lege), lo cierto es que, al pronunciarse sobre la cuestión en relación con la regulación belga, habiendo transcurrido solo tres años, la situación ha evolucionado de modo ininterrumpido.

En términos generales, en atención al reconocimiento de la amplitud de la cláusula estructural al sistema convencional, del margen de apreciación nacional, y en relación con la específica cuestión a debate. Pues, desde entonces, es decir, desde aquella inicial regulación nacional, se asiste, en el espacio europeo, así como a la puntual replicación de formulaciones legislativas en línea con esa variante franco-belga (desde hace pocos meses, esa es la situación en Dinamarca, por mencionar otro ejemplo), a la diversa previsión de aplicación a propósito de las exigencias de orden público, incluso con ese mismo carácter preventivo que resulta de una prohibición de acceso, si no extensiva a la deambulación por la plaza pública, aplicable a concretos medios de transporte, edificios y espacios públicos (como exponente de esta otra modalidad de prohibición parcial puede tomarse la reciente legislación de los Países Bajos).

A la altura de 2018, el precautorio estándar sentado por el TEDH en S.A.S. c. Francia no solo no se enjuicia ya, sin excepción, del intenso modo crítico en que ello pudo haberse hecho al hilo de la inmediata lectura de la cláusula de convivencia que, prescindiendo del contexto democrático nacional de referencia, podía parecer ajena a la función de salvaguarda de la garantía convencional de inmunidad de coacción de manifestaciones relativas a las creencias, sino que, entre tanto, cuenta con un cierto soporte político y comprensión doctrinal.

Soporte político encuentra esa cláusula jurisprudencial, así como en el respectivo espacio nacional, en el seno del Consejo de Europa (así, en particular, cf. Resolución de la Asamblea parlamentaria, n. ${ }^{\circ}$ 2076, 2015, Freedom of Religion and living together in a democratic society). Y a propósito de la comprensión doctrinal, sin excluir por ello posibles lecturas contradictorias con la noción misma de libertades y derechos fundamentales (así, en particular, la que pretendiese entender esa llamada a la convivencia, como operativo límite al ejercicio de libertades y derechos fundamentales, como una mera variante de imposición a las minorías de la moral mayoritaria, aun si se presentase articulada en forma de ley democrática), no es ya inusitada la propuesta de lecturas comprensivas que, en clave constitucional (es decir, integrando la subjetividad ius fundamental en un marco democrático de intercambio de razones públicas ${ }^{20}$ ), enfocan el asunto desde planteamientos éticos de

20 Cf., por otros, RAWLS, The Idea of Public Reason Revisited, en University of Chicago Law Review, vol. 84, n. $^{\circ}$ 3, pp. $765-807,1997$. 
responsabilidad y autonomía moral ${ }^{21}$, desde los que entender mejor la limitación democrática del ejercicio de las libertades y derechos fundamentales ${ }^{22}$.

\section{UNA CONSIDERACIÓN FINAL, A MODO DE CONCLUSIÓN}

Si bien se mira, y de los dos casos tomados en consideración no otra cosa resulta, en la jurisprudencia reciente del TEDH se advierte, en relación con las cuestiones morales abiertas en sociedades de plural confluencia sin perjuicio de sus respectivos acervos culturales/cultuales, un cierto giro republicano, mediante reafirmación de una prístina subsidiariedad de su función jurisdiccional en el marco del $\mathrm{CEDH}$, consecuente con la extensiva invocación del margen de apreciación nacional. Pero ya no en el marco de una lógica constitucional asentada en sociedades relativamente homogéneas, sino en un diverso contexto de heterogeneidad que, si ha de respetar los procesos democráticos de articulación de los respectivos debates morales en el ejercicio de una presupuesta discrecionalidad reguladora, precisa de una jurisprudencia convencional que se limite «en lo posible» al casuístico establecimiento del mínimo común denominador.

«En lo posible» significa aquí, sobre todo, que la discrecionalidad resultante del amplio margen de decisión nacional no podría llegar, como si de un sistema convencionalmente desatado se tratase, a la mera articulación de regímenes de tolerancia del otro; pues, en el seno de sociedades abiertas, la convivencia social (que como directriz tiene señalado incluso un día internacional, el 16 de noviembre de cada año), es presupuesto de encuentro de identidades sujetas todas ellas a la ley (sujeta, por su parte, a los contenidos esenciales de derechos, limitables, pero irrenunciables e indisponibles a voluntad de terceros, particulares o autoridades).

La dificultad de hacer bueno ese aserto, no estaría tanto en aquellos supuestos en los que (como en Osmanoglou y Kocabas c. Suiza) el acomodo es posible, mediante ensayo de conciliación de las exigencias ius fundamentales y de los deberes propios de situaciones de especial sujeción, cual es el caso, en relación con el cumplimiento de un régimen escolar que prima la faceta integrativa de la enseñanza, como en aquellos otros supuestos en los que, en presencia de una regla legal de prohibición de acceso a la vía pública, una persona que porte una determinada vestimenta, al amparo de su intimidad y sus creencias, invoque su libertad de auto determinación personal en pretendida consecuencia con el desenvolvimiento de su propio plan de vida (cual fuera, a su modo, el caso en S.A.S. c. Francia).

En una sociedad constitucionalmente bien constituida, de tolerancia no cabría hablar en un sentido vertical, en ninguna dirección, sino solo en un sentido horizontal, entre los sujetos a la ley (común). Y, en particular, al efecto de prevenir brotes de intolerancia, pues - así como en los procesos quirúrgicos, si vale el símil organicista, alude a

21 Cf., por otros, APPIAH, Ética de la identidad, Buenos Aires, 2007.

22 En esa línea morigerada de reflexión, mirando a la casuística jurisprudencia del TEDH, se concluye que «en vez de criticar la < convivencia > como un valor arbitrario en el Convenio, es hora ya de imbuir el sistema ius fundamental del Convenio europeo de la interpretación (que sea) más compatible con los valores fundamentales de respeto mutuo e igual protección subyacente a los derechos humanos, a la moralidad política y al CEDH como un todo» (líneas conclusivas de Trispiotis, Two Interpretations of «Living Togheter» in European Human Rights Law, en European Human Rights Law Journal, 73, 3, 2016 pp. 580-607). 
una especie de reactiva respuesta inmunitaria frente a antígenos, propios o extraños-, en situaciones de «trasplante» cultural/cultual, la tolerancia del «cuerpo social» no se mide tanto por el grado de desatención o indiferencia, como por su reactiva respuesta.

$Y$, en ese sentido, la cuestión se complica en casos de falencia y quiebras de la convivencia que, de no remediarse, puedan llegar a generar desconfianza en la plaza pública de un modo gradual hasta un cierto punto de no retorno; la duda está en saber si, antes de llegar a la hipótesis de ruptura (mediante la articulación política de discursos reaccionarios), cabría o no la adopción de prevenciones, ante comportamientos, actitudes o conductas, a los que se vendría a oponer, si no la intolerancia, sí una «tolerancia cero»; lo que, llevado al asunto S.A.S. sería tanto como preguntarse, si el establecimiento de una obligada exigencia de no deambular en la plaza pública con una vestimenta que oculta el rostro, sancionable en caso de incumplimiento de la prohibición (dado que no alcanza al conjunto de los ciudadanos, sino solo a quienes se comportasen del modo que se excluye o/y prohíbe), en tanto que manifestación ex lege de «tolerancia cero», podría considerarse o no compatible con una lectura constitucional de la cláusula de orden público; si, por su faceta de normativa prohibición y sanción de comportamientos, aun fungiendo como norma general de prevención, podría cohonestarse ya con el principio general de libertad que está en la base del constitucionalismo de los derechos, del que la constitutiva regla revolucionaria, según la cual estaría permitido hacer todo aquello que no prohíba el legislador, desde su formulación en el artículo 4 de la Declaración de 1789, hace parte, integrando el acervo propio del constitucionalismo francés.

$* * *$

TITLE: From the subjective to the objective in the conventional jurisprudence, in two examples

ABSTRACT: The recent case law of the European Court of Human Rights shows a certain modulation, from the subjective to the objective, in a context of controversial national reconsideration of the open societies of Europe in crisis. This is what we are dealing with here in the light of two manifestations of conflicts of different sizes and scope; purposefully, one, of the inclusive field of education, and relative, the other, to the regulation of access to public space by means of excluding rules, of general prevention, supposedly instrumental to ensuring the safeguarding of coexistence, of living together.

RESUMEN: En la reciente jurisprudencia del TEDH se advierte una cierta modulación, de lo subjetivo a lo objetivo, en un contexto de controvertida reconsideración nacional de las sociedades abiertas de la Europa en crisis. De ello se trata aquí atendiendo a dos manifestaciones de conflictos de diverso porte y alcance; a propósito, la una, del inclusivo ámbito de la enseñanza, y relativa, la otra, a la regulación de acceso al espacio público mediante reglas excluyentes, de prevención general, pretendidamente instrumentales al aseguramiento de la salvaguarda de la convivencia, de la vida en común.

KEY WORDS: European Court of Human Rights, subjective and objective Protection; inclusive Education; legal Probibition of face simulation in public Space; general Prevention of public order; safeguarding living together.

PaLABRAS CLAVE: Tribunal Europeo de Derechos Humanos, tutela subjetiva y objetiva; enseñanza inclusiva; ley de probibición de simulación del rostro en el espacio público; prevención general del orden público; salvaguarda de la convivencia.

FECHA DE RECEPCIÓN: 24.08.2018

FECHA DE ACEPTACIÓN: 13.09.2018 